\title{
Using Satellite Data to Calculate DimethylSulfide in Greenland Sea
}

\author{
Li Zhao ${ }^{1}$ and $\mathrm{Bo} \mathrm{Qu}^{2, *}$ \\ ${ }^{1,2}$ Nantong University, China \\ ${ }^{*}$ Corresponding author
}

\begin{abstract}
We use satellite data to calculate Dimethylsulfur (DMS) in Greenland Sea $\left(20^{\circ} \mathrm{W} 10^{\circ} \mathrm{E}, 70^{\circ} \mathrm{N} 80^{\circ} \mathrm{N}\right)$ in year 2003 2006. At the same time, explore the correlations between DMS and sea-ice concentration (ICE). Among the huge global satellite data, the chlorophyll a (CHL) and sea-ice concentration data were retrieved in the study region. MATLAB software is used to convert the regional data to grid data. The temperature difference method is used to calculate the mixed layer depth (MLD). DMS is calculated according to the Simó's formula. Furthermore, we divided the study region into three sub-regions $70^{\circ} \mathrm{N} \sim 75^{\circ} \mathrm{N}$ and $75^{\circ} \mathrm{N} \sim 80^{\circ} \mathrm{N}$ and $70^{\circ} \mathrm{N} \sim 80^{\circ} \mathrm{N}$ ). Statistical software SPSS is used for correlation and regression analysis. Results show that there were negative correlations between DMS and ICE. The correlation coefficients between DMS and ICE are in the range $-0.57 \sim-\mathbf{- 0 . 4 5}$. The way of handling satellite data, calculating methyl sulfur and correlation analysis can be valuable references for the biogeochemistry researchers.
\end{abstract}

Keywords- dimethyl sulfide(DMS); satellite data; chlorophyll a(CHL); mixed layer depth(MLD)

\section{INTRODUCTION}

In 1972, Lovelock et al. [1] discovered the dimethylsulfide (DMS) in seawater for the first time. The ocean provides half of the biogenic sulfide which is discharged into the atmosphere. The sulfur released of DMS from seawater accounts for $23 \%$ of the total sulfur in the global atmosphere, which accounts for about $90 \%$ of the total sulfur flux [2]. DMS flux in sea surface water emits into the atmosphere after being oxidized to non-sea salt sulfate (NSS $-\mathrm{SO}_{4}^{2-}$ ), which increases the number of cloud condensation nuclei (CCN). The increase in CCN strengthens reflectivity of the clouds to the sun, reduces global heat income, thereby reduces the greenhouse effect[3]. The main source of sulfate aerosols is the oxidation products of DMS in the atmosphere. DMS is an important factor of acid rain [4]. $\mathrm{SO}_{2}$ and MSA (methane sulfonic acid) were synthesized by some free radical such as DMS 、 $\mathrm{OH}$ (hydroxide) and $\mathrm{NO}_{3}$ (nitrogen oxides) from the ocean into the atmosphere, and then through the homogeneous reaction to produce non-sea salt sulfate (NSS). Most of these oxidation products have strong acidity, which can reduce the $\mathrm{pH}$ value of rainwater, then have an important impact on the natural acidity of precipitation, and produce acid rain [5]. Thus, DMS is closely related to global environmental change. It has become one of the hotspots in the research of global environmental changes.
Nowadays, there are extensive researches on dimethylsulfide worldwide. NOAA has compiled a global 21000 DMS seawater concentration data. In 2001, Anderson et al. [10] calculated the DMS value according to chlorophyll concentration $\mathrm{C}$, daily illumination efficiency $\mathrm{J}$ and the amount of nutrients (dimensionless) Q. In 2002, Simó et al. had obtained the relationship between DMS and CHL together with MLD[7]. In 2004, Belviso et al. computed DMS directly by chlorophyll, according to community structure index. In the same year, Gabric improved the Simó formula [8].

Different from the oversea researches, most of the domestic studies are limited to the extraction of domestic ocean data by physical chemistry experiments. For example, Zhang et al. (2009) studied biogenic emission of DMS from the North Yellow Sea and its contribution to Non-Sea-Salt sulfate in Aerosol [9] Zhang MiMing et al (2013) studied the DMS sea-air exchange process in the southern ocean [5].

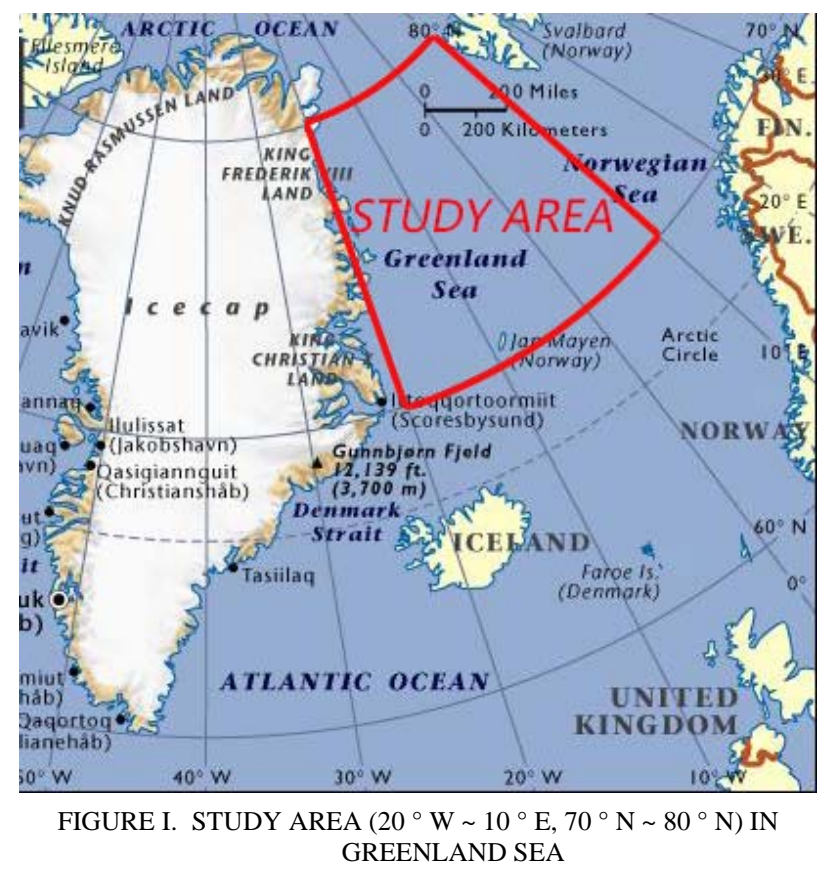

The Arctic Ocean is surrounded by the mainland. It is an almost enclosed sea and is known as the fourth largest ocean in the world. Among four oceans, the Arctic Ocean is the smallest and the average depth is the lowest. It has seven affiliated sea, Greenland is one of them. Greenland Sea (GS) 
located in the east of Greenland, northern latitude between $66^{\circ} \sim 80^{\circ}$ (Figure I). GS is the main outlet of Arctic Ocean to the North Atlantic Ocean. The majority of Greenland Sea surface currents derived from either warmer, more saline North Atlantic current from south and colder, less saline Arctic water from north.

Due to lacking of DMS data in the Arctic Ocean, we need to use the CHL satellite data together with extracted MLD data) to calculate DMS concentrations in our study region. Getting coherent historical data is important to the further studies.

\section{DATA SOURCES AND RESEARCH MethodS}

\section{A. Data Sources}

CHL (mg per cubic meter) is retrieved from NASA Ocean Color MODIS/Aqua archive Level 3 (4-km, 8-day mapped data (http://oceandata.sci.gsfc.nasa.gov/). SeaDAS (SeaWiFS Data Analysis System) software was then used for regional data $\left(20^{\circ} \mathrm{W} \sim 10^{\circ} \mathrm{E}, 70^{\circ} \mathrm{N} \sim 80^{\circ} \mathrm{N}\right)$ processing for year 2003-2006. Effort are made for retrieving MLD source data. CTD temperature data are drived from the International Arctic Research Center (http: //oregon.iarc.uaf. edu / dbaccess.html). The detailed data processing methods are introduced in this section.

\section{B. Calculation Method of DMS}

Simó formula is used to calculate the regional DMS concentrations. The formula is only dependent on CHL and MLD concentrations for different ratos [7]:

Simó formula:

$$
D M S=-\ln (M L D)+5.7, \quad C H L / M L D<0.02
$$

$D M S=55.8(C H L / M L D)+0.6, C H L / M L D \geq 0.02$

\section{DATA EXTRACTION}

\section{A. CHL Data Processing}

- The CHL data downloaded from NASA Ocean Color is a series of compressed files with the suffix .bz2 and L3M_8D_CHL_CHLOR_A_4KM file will be obtained after decompression. This file can be opened or have a preliminary treatment with professional software SeaDAS. The site data is divided according to time and the downloaded data is global data. By using SeaDAS software, we extracted the range 2003 to 2006 Greenland Sea $\left(20^{\circ} \mathrm{W} \sim 10^{\circ} \mathrm{E}, 70^{\circ} \mathrm{N} \sim\right.$ $80^{\circ} \mathrm{N}$ ) data of CHL.

- Extract the individual data files can be opened using Excel, the data matrix is a $8 \times 101071$, the huge amount of information, contains many invalid data. Therefore, we restricted to our study region, using MATLAB to process the irregular huge amount data into $30 \times 10$ grid data for the study region.

\section{B. MLD Data Processing}

- Mixed layer depth (MLD) of CTD (conductivity temperature depth) data is from the Arctic Ocean Survey database. The survey data came from United States, Russia, Sweden, Japan, China and other nine countries. Since the site data is divided according to geographical location, we only need to select our own research area (Greenland Sea $20^{\circ} \mathrm{W} \sim 10^{\circ} \mathrm{E}, 70^{\circ} \mathrm{N}$ $\sim 80^{\circ} \mathrm{N}$ ). WodC.exe is a given program used for the downloaded file visualization, into usable Notepad to open the data (Figure 2)

- CTD file contains three basic measuring physical parameters of water conductivity, temperature and depth of water. According to these three parameters, we can study the physical and chemical properties of water, water layer structure and water movement, calculated a variety of other physical parameters, such as sound velocity, mixed layer depth and so on. We also extracted the range from 2003 to 2006 data, the temperature difference method is used [12], namely the MLD data is calculated from the depth of temperature differences from the surface water $\left(0.5{ }^{\circ} \mathrm{C}\right.$ lower than the surface water). $\mathrm{R}$ statistical software is used for calculating grid MLD data.

- However, compared to the CHL data, MLD data is relatively small. We accepted the error (0.5 \pm $0.15){ }^{\circ} \mathrm{C}$. Due to the huge amount of data, manual screening data clearly undesirable, Matlab program is used for semi-automatic filtering out the required data for analysis (Figure II).

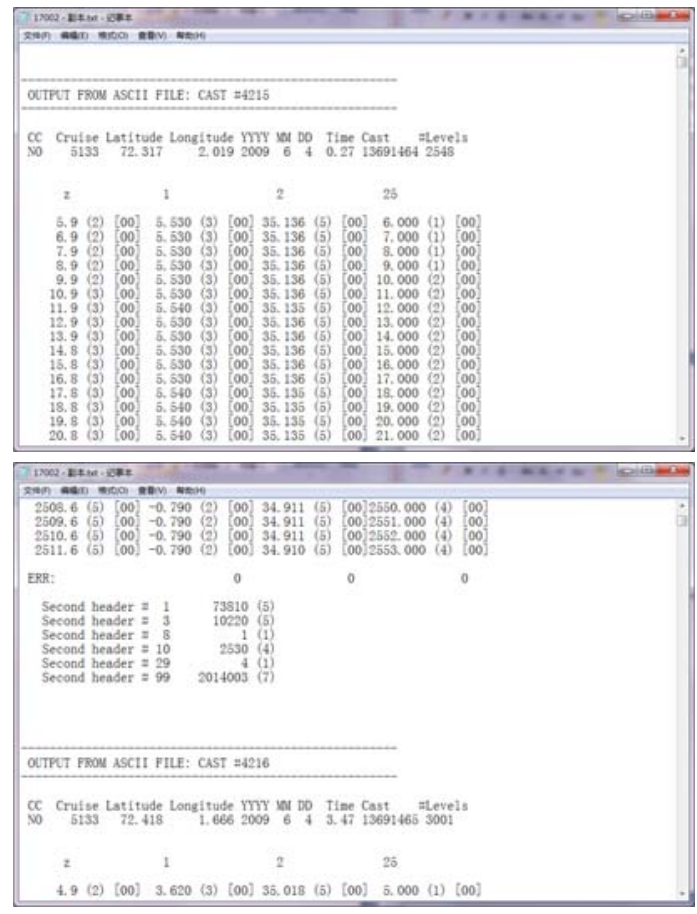

FIGURE II. VISUALIZATION CTD FILE 


\section{RESUlt ANALYSIS}

\section{A. CHL's Distribution}

Due to Arctic special climate conditions (half year darkness), within our study region $\left(20^{\circ} \mathrm{W} \sim 10^{\circ} \mathrm{E}, 70^{\circ} \mathrm{N}\right.$ $\sim 80^{\circ} \mathrm{N}$ ), annual CHL data is only valid from March to September. The interannual variations are found for regional average history time series. Based on comparison of the annual CHL concentrations, CHL annual peaks are in June, CHL minimum concentrations are in March. The general CHL trend is increasing from March and reached peak in June then decreasing to September (Figure III). For a more accurate analysis, we divided the study region into two sub-region: $70^{\circ}$ $\mathrm{N} \sim 75^{\circ} \mathrm{N}$ and $75^{\circ} \mathrm{N} \sim 80^{\circ} \mathrm{N}$. CHL distributions have some differences among the two sub-region. When CHL concentrations are generally relative higher in $70^{\circ} \mathrm{N} \sim 75^{\circ} \mathrm{N}$ comparing to northern region $75^{\circ} \mathrm{N} \sim 80^{\circ} \mathrm{N}$. . In year 2003 and 2004, CHL concentrations are relatively higher in $70^{\circ} \mathrm{N}$ $\sim 75^{\circ} \mathrm{N}$ region and in year 2005 and 2006, CHL concentrations are higher in $75^{\circ} \mathrm{N} \sim 80^{\circ} \mathrm{N}$ region.

\section{B. MLD's Distribution}

In the study region for year 2003-2006, MLD distributions also have interannual variations. Based on a comparison of the annual MLD line chart, MLD distributions over time have similar to a concave parabolic patterns, MLD reached to its peak in March and reached to its minimum in July. Generally, MLD is shallower in summer and deeper winter.

There are two different MLD distributions in $70^{\circ} \mathrm{N} \sim 75^{\circ}$ $\mathrm{N}$ and $75^{\circ} \mathrm{N} \sim 80^{\circ} \mathrm{N}$ two sub-region. In $70^{\circ} \mathrm{N} \sim 75^{\circ} \mathrm{N}$ region, MLD profiles are more evenly distributed, and in $70^{\circ}$ $\mathrm{N} \sim 80^{\circ} \mathrm{N}$ region, MLD values are much smaller. Obviously, MLD distributions have effect by regions (Figure III).

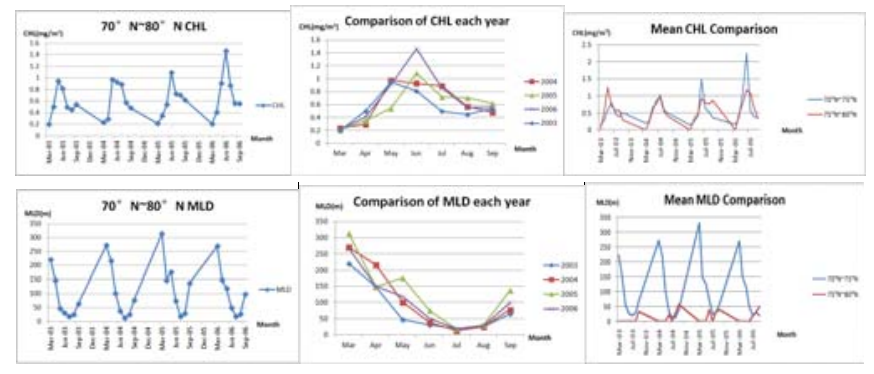

FIGURE III. CHL AND MLD, DISTRIBUTIONS AND COMPARISONS

\section{DMS's distribution}

Using Simó formula (1), (2), DMS concentration is calculated based on CHL and MLD concentrations.

DMS monthly data in $70^{\circ} \mathrm{N} \sim 80^{\circ} \mathrm{N}$, from 2003 to 2006 is shown in figure. DMS has also interannual variations. DMS concentrations are peaked in May or June and reached to minimum in March or September (Figure IV).

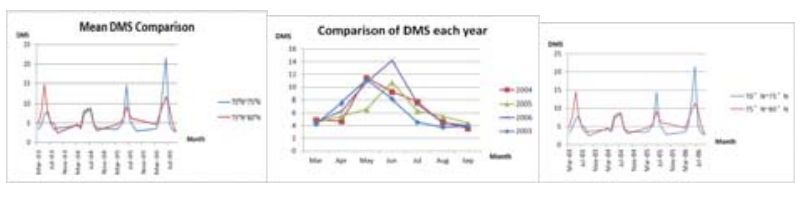

FIGURE IV. DMS DISTRIBUTIONS AND COMPARISONS

The DMS concentrations in the sub-region $\left(70^{\circ} \mathrm{N} \sim 75^{\circ}\right.$ $\mathrm{N}$ and $75^{\circ} \mathrm{N} \sim 80^{\circ} \mathrm{N}$ ) for year 2003 to 2006 are also studied. DMS concentrations are higher in $75^{\circ} \mathrm{N} \sim 80^{\circ} \mathrm{N}$ compared to $70^{\circ} \mathrm{N} \sim 75^{\circ} \mathrm{N}$ in 2005 and 2006. The data are relatively unstable due to the universal formula we used. More accurate DMS field data is urged for further more accurate analysis.

\section{Relationships between DMS, and ICE}

Sea Ice concentration (ICE) is also studied. ICE had peaks in March and valleys in September. ICE was in the range of $45-57 \%$ and had a decreased trend in year 2003-2005. It is higher in north (8-55\%) and lower in south (0-20\%) in the sun-region. SPSS statistics software is used for the correlation analysis. The correlation coefficients between DMS and ICE are within the range of $-0.58 \sim-0.45$. The regression equation is:

$$
D M S=-0.981+2.003 \times I C E-0.108 \times I C E^{2}+0.002 \times I C E^{3}
$$

In the $70^{\circ} \mathrm{N} \sim 75^{\circ} \mathrm{N}$ sub-region, regression equation is:

$$
D M S=10.4-0.88 \times I C E-0.03 \times I C E^{2}, R^{2}=0.369
$$

In the $75^{\circ} \mathrm{N} \sim 80^{\circ} \mathrm{N}$ sub-region, regression equation is:

$$
D M S=-4.05+1.54 \times I C E-0.51 \times I C E^{2}, R^{2}=0.473
$$

\section{CONCLUSION AND PROSPECT}

Due to the difficulties of obtaining DMS field data in remote Arctic ocean, the CHL and MLD data can be obtained by processing a large number of satellite data, and using simo's formula [7], DMS can be calculated. CHL and MLD profiles have interannual variations, so are the calculated DMS concentrations. Due to the half year darkness in Arctic Ocean, satellite data of CHL is only valid from March to September. DMS concentrations peaked in May or June and reached to minimum in March or September. In 2003, DMS in northern region was higher. The reason was possibly due to the melting ice. DMS concentrations have an increased trend in recent years.

SPSS, MATLAB SEADAS and R software were used for our data processing. However, there are still many data needs to be handled manually, which existed for errors and errors that are difficult to avoid. MLD data is also lacking. We used temperature difference method and accepted $0.15{ }^{\circ} \mathrm{C}$ of the error which slightly affected the accuracy of the final results. 
Divided two parts $\left(70^{\circ} \mathrm{N} \sim 75^{\circ} \mathrm{N}, 75^{\circ} \mathrm{N} \sim 80^{\circ} \mathrm{N}\right.$ ) to analyze respectively, it is a way to eliminate accidental errors.

Statistical analysis interspersed. More accurate DMS concentrations in Arctic are expected to carry out more accurate DMS researches related to climate changes.

\section{ACKNOWLEDGMENT}

Special thanks to NASA's Ocean Biology Processing Group for providing MODIS aqua, Level 3 (4-km equirectangular projection) 8-day mapped data for chlorophyll-a (CHL). Thank to MSc senior classmate Meifang Zeng for the guidance of MLD data retrieval. Thanks for the National Natural Science Foundation of China (Funding No. 41276097) for providing funding for this project.

\section{REFERENCES}

[1] J.E. Lovelock, R.J. Maggs, R.A. Rasmussen, Atmospheric Dimethyl Sulphide and the Natural Sulfur Cycle, Nature, 237 (1972) 452-453.

[2] M. Chin, D.J. Jacob, Anthropogenic and natural contributions to tropospheric sulfate: A global model analysis, Journal of Geophysical Research Atmospheres, 1011 (1996) 18691-18700.

[3] G.P. Yang, C.X. Li, Biologic Processes That Influence the Production of Dimethylsulfide (DMS) from Marine Phytoplankton, Periodical of Ocean University of China, 39 (2009) 453-460.

[4] H.Y. Li, D.Z. Wang, Y.M. Lin, H.S. Hong, Progress in Study of Marine Dimethylsulfide, Jorunal of Xiamen University (Natural Science), 40 (2001) 715-725.

[5] M.M. Zhang, L.Q. Chen, J.J. Wang, Advances in Studying the Sea-Air Dimethysulphide Exchange Process in the Southern Ocean, Advances in Earth Science, 28 (2013) 1015-1024.

[6] M. Hu, X.Y. Li, J.L. Li, Z.J. Yu, Dimethylsulfide in Sea Water in the Gulf of JiaoZhou, Act A Scientia E Circu Mstantiae, 17 (1997) 80-85.

[7] R. Simó, J. Dachs, Global ocean emission of dimethylsulfide predicted from biogeophysical data, Global Biogeochemical Cycles, 16 (2002) 2621 \& ndash; 26-10.

[8] A.J. Gabric, R. Simo, RA Cropp, A. Hirst, J. Dachs, Modeling estimates of the global emission of dimethylsulfide under inflammatory greenhouse conditions, Global biogeochemical cycles, 18 (2004).

[9] H.H. Zhang, G.P. Yang, Biogenic Emission of Dimethylsulfide(DMS) from the North Yellow Sea and Its Contribution to Non-Sea-Salt Sulfate in Aerosol, Periodical of Ocean University of China, 39 (2009) 750-756 The

[10] T.R. Anderson, S.A. Spall, A. Yool, P. Cipollini, P.G. Challenor, M.J.R. Fasham, Global fields of sea surface dimethylsulfide predicted from chlorophyll, alive, light, Journal of Marine Systems, 30 (2001) 1-20.

[11] S. Belviso, C. Moulin, L. Bopp, J. Stefels, Assessment of a global climatology of oceanic dimethylsulfide (DMS) inputs based on SeaWiFS imagery (1998-2001), Canadian Journal of Fisheries \& Aquatic Sciences, 61 (2004) 804-816.

[12] M.F. Zeng, B. Qu, Time Characteristic and Relationship of Mixed Layer Depth with Ice Cover, Journal of Nantong University(Natural Science Edition), 13 (2014) 75-80. 